\title{
Polycythemia vera and hydroxyurea resistance/intolerance: a monocentric retrospective analysis
}

\author{
T. Demuynck ${ }^{1} \cdot$ G. Verhoef ${ }^{2} \cdot$ M. Delforge ${ }^{2} \cdot$ P. Vandenberghe ${ }^{2,3} \cdot$ Timothy Devos $^{2,4}$
}

Received: 14 November 2018 / Accepted: 2 March 2019 / Published online: 27 March 2019

(C) Springer-Verlag GmbH Germany, part of Springer Nature 2019

\begin{abstract}
Hydroxyurea (HU) resistance or intolerance occurs in 15 to $24 \%$ of patients with polycythemia vera (PV). Resistance to HU is associated with a shortened life expectancy, intolerance has no prognostic value. We assessed the occurrence of HU resistance or intolerance comparing the original (ELNo) versus the modified European Leukemia Net (ELNm) criteria as applied in recent large clinical trials including PV patients. We retrospectively analyzed 106 patients with PV treated with $\mathrm{HU}$ at the University Hospitals of Leuven between 1990 and 2016 for occurrence of HU resistance/intolerance when using both ELNo as ELNm. After a mean duration of treatment of 5.1 years, when applying the ELNo $20.7 \%$ of patients had shown resistance or intolerance to HU in comparison to $39.6 \%$ when using the ELNm. When using the ELNo $4.7 \%$ of patients were resistant to HU versus $23.6 \%$ when applying the ELNm. In total, $16.0 \%$ of patients were HU intolerant. This rate was identical when using both ELNo and ELNm. $20.7 \%$ of PV patients were considered as HU-resistant or intolerant when using the original ELN criteria. However, when applying the modified ELN criteria $39.6 \%$ of PV patients were resistant or intolerant to HU. In our hands, no patient received a minimum dose of $2 \mathrm{~g} \mathrm{HU}$ a day, as such the ELNm seem better adapted for daily clinical use. However, the prognostic value of HU-resistance in PV, when defined by the ELNm, still needs to be confirmed.
\end{abstract}

Keywords Polycythemia vera $\cdot$ Hydroxyurea resistance/intolerance $\cdot$ Ruxolitinib $\cdot$ European leukemia net criteria

\section{Introduction}

$\mathrm{PV}$ is a myeloproliferative neoplasm characterized by clonal stem-cell proliferation of multipotent hematopoietic progenitors, leading to abnormal production of red blood cells the erythroid, megakaryocytic and myeloid lineages [1-3]. Nearly all patients with PV have an acquired mutation of Janus Kinase 2 (JAK2). The JAK2V617F and JAK2 exon 12 mutation have been detected in $95 \%$ and $3 \%$ of PV patients, respectively [4]. PV is associated with an increased risk of

Timothy Devos

timothy.devos@uzleuven.be

1 Department of Internal Medicine, University Hospitals of Leuven, Leuven, Belgium

2 Department of Hematology, University Hospitals of Leuven, Herestraat 49, 3000 Leuven, Belgium

3 Department of Human Genetics, KU Leuven, Leuven, Belgium

4 Laboratory of Experimental Transplantation, Department of Microbiology and Immunology, KU Leuven, Leuven, Belgium thrombosis and progression to myelofibrosis or acute myeloid leukemia [5-7]. Patients with PV have a considerable symptom burden including pruritus and constitutional symptoms such as fatigue and night sweats [8-10]. Aggressive control of hematocrit levels with target values below $45 \%$ lowers the risk of cardiovascular death or major thrombosis [11]. Control of hematocrit can be achieved through phlebotomy and/or cytoreductive therapy. Cytoreductive therapy is recommended for high risk patients defined by the risk for thrombosis [12-16]. The first-line cytoreductive treatment of choice currently is hydroxurea [17-19]. Inadequate response or resistance to $\mathrm{HU}$ occurs in 5 to $11 \%$ of PV patients and is associated with a shortened survival [20-22]. Approximately 5$13 \%$ of patients treated with HU develop unacceptable side effects such as leg ulcers, drug-induced fever, or mucocutaneous manifestations [19-21]. Intolerance to HU has no prognostic significance. A unified definition of resistance and intolerance to $\mathrm{HU}$ has been defined by the European LeukemiaNet (ELN) [23]. These criteria were initially defined to identify a subgroup of patients who could benefit from second-line treatment. Until recently, patients with HU resistance/intolerance had few therapeutic alternatives in some 
European countries, as interferons are not reimbursed for PV patients. Ruxolitinib, a JAK1/2 inhibitor, has been evaluated in PV patients with HU resistance and intolerance in the RESPONSE and RESPONSE-2 trials [24, 25]. These trials used a modification of the ELN criteria. Instead of the minimum dose of $2 \mathrm{~g}$ of $\mathrm{HU}$ a day as defined in the original ELN criteria (ELNo), the maximum tolerated dose was used in the modified ELN criteria (ELNm).

The objective of our current study is to examine the rate of $\mathrm{HU}$ resistance/intolerance of patients with PV who were treated at the University Hospitals of Leuven and to compare the frequency of $\mathrm{HU}$ resistance/intolerance according the ELNo versus the ELNm.

\section{Material and methods}

This study is a monocentric retrospective analysis of patients with PV treated with HU at the University Hospitals of Leuven in Leuven, Belgium, from 1990 until 2016. The study was approved by the Ethics Committee of the University Hospitals of Leuven. Informed consent was obtained from all patients for being included in the study. In all patients, the diagnosis of PV was assessed using the criteria of the World Health Organization applicable at time of diagnosis. The indication for cytoreductive treatment with $\mathrm{HU}$ was decided by the attending hematologist based on the clinical guidelines at that time. In all patients, when available, the main clinical data at time of diagnosis were collected including age, sex, PV-related symptoms (microvascular symptoms and pruritus), history of thrombosis or thrombosis at diagnosis and the presence of palpable splenomegaly. Hematological data at time of diagnosis such as hemoglobin level, white blood cell

Table 1 Original ELN criteria for HU resistance/intolerance [23]

1. Need for phlebotomy to keep hematocrit $<45 \%$ after 3 months of at least $2 \mathrm{~g}$ /day of HU OR

2. Uncontrolled myeloproliferation, i.e., platelet count $>400 \times 10^{9} / \mathrm{L}$ and white blood cell count $>10.0 \times 10^{9} / \mathrm{L}$ after 3 months of at least $2 \mathrm{~g} /$ day of HU OR

3. Failure to reduce massive ${ }^{\dagger}$ splenomegaly by more than $50 \%$ as measured by palpation OR failure to completely relieve symptoms related to splenomegaly after 3 months of at least $2 \mathrm{~g} /$ day of HU OR

4. Absolute neutrophil count $<1.0 \times 10^{9} / \mathrm{L}$ OR platelet count $<100 \times 10^{9} / \mathrm{L}$ or hemoglobin $<10.0 \mathrm{~g} / \mathrm{dL}$ at the lowest dose of $\mathrm{HU}$ required to achieve a complete or partial clinicohematological response, $\mathrm{OR}$

5. Presence of leg ulcers or other unacceptable HU-related non-hematological toxicities, such as mucocutaneous manifestations, gastrointestinal symptoms, pneumonitis or fever at any dose of $\mathrm{HU}$

$H U$ hydroxyurea

${ }^{\dagger}$ Organ extending by more than $10 \mathrm{~cm}$ from the costal margin count, platelet count and JAK2 mutation status were also recorded. The duration of therapy with HU was recorded. Occurrence of resistance/intolerance was registered using both ELNo (Table 1) for HU resistance/intolerance and ELNm (Table 2), as used in the RESPONSE trials [13, $25,26]$. Instead of using a minimum dose of $2 \mathrm{~g}$ of $\mathrm{HU}$ a day, the modified ELN criteria used the maximum tolerated dose. Resistance to HU was defined as fulfilling one of the first four criteria (criterion 1-4, Table 1 and 2). Intolerance was defined as presence of unacceptable HU-related non-hematological toxicities (criterion 5, Table 1 and 2.

The initial survey included 133 patients. Twenty patients did not meet the World Health Organization criteria for PV applicable at time of diagnosis or had an unclear differential diagnosis with myelodysplasia or other myeloproliferative neoplasms such as essential thrombocytosis or primary myelofibrosis. Two patients, initially treated at another hospital, were excluded because of absence of 1 year of follow-up at our center prior to evolution to post-PV myelofibrosis (PPVMF). Five patients were lost to follow-up. In total, 106 patients were included in this study.

\section{Results}

\section{Patient characteristics}

A total of 106 patients were included in this retrospective study. Their main clinical and hematological characteristics at time of diagnosis are shown in Table 3. Regarding antithrombotic therapy, 93 patients $(87.7 \%)$ were treated with a low-dose aspirin, three patients $(2.8 \%)$ were treated with clopidogrel without a low-dose aspirin, six patients (5.66\%)

Table 2 Modified ELN criteria for HU resistance/intolerance [25, 26]

1. Need for phlebotomy to keep hematocrit $<45 \%$ after 3 months of at least $2 \mathrm{~g}$ /day OR a maximum tolerated dose OR

2. Uncontrolled myeloproliferation, i.e., platelet count $>400 \times 10^{9} / \mathrm{L}$ And white blood cell count $>10.0 \times 10^{9} / \mathrm{L}$ after 3 months of at least $2 \mathrm{~g} /$ day OR a maximum tolerated dose OR

3. Failure to reduce massive ${ }^{\dagger}$ splenomegaly by more than $50 \%$ as measured by palpation OR failure to completely relieve symptoms related to splenomegaly after 3 months of at least $2 \mathrm{~g} /$ day OR maximum tolerated dose OR

4. Absolute neutrophil count $<1.0 \times 10^{9} / \mathrm{L}$ OR platelet count $<100 \times 10^{9} / \mathrm{L}$ or hemoglobin $<10.0 \mathrm{~g} / \mathrm{dL}$ at the lowest dose of HU required to achieve a complete or partial clinicohematological response, OR

5. Presence of leg ulcers or other unacceptable HU-related non-hematological toxicities, such as mucocutaneous manifestations, gastrointestinal symptoms, pneumonitis or fever at any dose of HU.

$H U$ hydroxyurea

${ }^{\dagger}$ Organ extending by more than $10 \mathrm{~cm}$ from the costal margin 
Table 3 Main clinicohematological characteristics at time of diagnosis

\begin{tabular}{ll}
\hline Clinicohematological characteristics & Value \\
\hline Number of patients & 106 \\
Median age, years (range) & $63(29-83)$ \\
Age above 60 years, $n(\%)$ & $59(55.7)$ \\
Male/female, $n$ & $59 / 47$ \\
History of thrombosis, $n(\%)$ & $19(22.4)$ \\
Microvascular symptoms, $n(\%)$ & $33(36.7)$ \\
Pruritus, $n(\%)$ & $16(17.6)$ \\
Thrombosis at diagnosis, $n(\%)$ & $12(12.9)$ \\
Palpable splenomegaly, $n(\%)$ & $13(14.9)$ \\
Hemoglobin, g/dL & \\
Male* & $19.2(15.0-23.1)$ \\
Female* & $19.1(14.9-22.9)$ \\
Hematocrit, $(\%)$ & \\
Male* & $58.2(35.0-70.0)$ \\
Female* & $58.1(46.5-70.7)$ \\
White blood cell count, $10^{9} / \mathrm{L}^{*}$ & $11.41(4.0-34.0)$ \\
$>10.0 \times 10^{9} / \mathrm{L}, n(\%)$ & $46(49.0)$ \\
$>15.0 \times 10^{9} / \mathrm{L}, n(\%)$ & $15(16.0)$ \\
Platelet count, $10^{9} / \mathrm{L} *$ & $472(80-1152)$ \\
$>450 \times 10^{9} / \mathrm{L}, n(\%)$ & $49(52.1)$ \\
$J A K 2$ mutation & \\
$V 617 F, n(\%)$ & $100(95.2)$ \\
Exon $12, n(\%)$ & $1(1.0)$ \\
No mutation, $n(\%)$ & $5(3.8)$ \\
\hline
\end{tabular}

*Data are median (range)

Table 4 Occurrence of HU resistance/intolerance: original versus modified ELN criteria received no antithrombotic therapy but anticoagulation (under form of vitamin $\mathrm{K}$ antagonist, direct thrombin or direct $\mathrm{Xa}$ inhibitor), and four patients $(3.77 \%)$ received no antithrombotic nor anticoagulant therapy.

\section{Complications}

After a median follow-up of 8.2 years, a total of nine thrombotic events were registered (seven arterial, two venous). There was no major bleeding. Progression to myelofibrosis occurred in 12 patients $(11.32 \%)$. The mean time of progression to myelofibrosis was 10.3 years. One patient showed evolution to AML, 19.0 years after the diagnosis. A total of 16 patients $(15.09 \%)$ died. Causes of death included transformation to myelofibrosis $(n=3)$, malignancy $(n=3)$, interstitial lung disease $(n=1)$, and unknown cause of death $(n=9)$.

\section{HU resistance/intolerance}

Assessment of resistance/intolerance to HU is shown in Table 4. The median length of treatment with HU was 5.1 years with a range from 0.1 to 24.8 years. When using the original ELN criteria, 22 patients $(20.7 \%)$ were resistant or intolerant, in comparison to 42 patients $(39.6 \%)$ when applying the modified ELN criteria (Table 4).

\section{Original ELN criteria (ELNo)}

When using the ELNo, 5 patients (4.7\%) were resistant to HU. No patient received a minimum dose of $2 \mathrm{~g}$ of $\mathrm{HU}$ a day for at

\begin{tabular}{lll}
\hline & Original ELN criteria & Modified ELN criteria \\
\hline Total patients, $n$ & 106 & 106 \\
Median length of treatment with HU, years* & $5.1(0.1-24.8)$ & $5.1(0.1-24.8)$ \\
Ongoing therapy, $n(\%)$ & $66(62.3)$ & $66(62.3)$ \\
Resistance/intolerance, $n(\%)$ & $22(20.7)$ & $42(39.6)$ \\
Resistance, $n(\%)$ & $5(4.7)$ & $25(23.6)$ \\
Hematocrit $>45 \%, n(\%)$ & $0(0.0)$ & $18(16.7)$ \\
Leukocyte count $>10.0 \times 10^{9} / \mathrm{L}, n(\%)$ & $0(0.0)$ & $1(0.9)$ \\
Platelet count $>400 \times 10^{9} / \mathrm{L}, n(\%)$ & $0(0.0)$ & $1(0.9)$ \\
Palpable splenomegaly, $n(\%)$ & $0(0.0)$ & $0(0.0)$ \\
Hemoglobin $<10.0 \mathrm{~g} / \mathrm{dL}, n(\%)$ & $1(0.9)$ & $1(0.9)$ \\
Neutrophil count $<1.0 \times 10^{9} / \mathrm{L}, n(\%)$ & $0(0.0)$ & $0(0.0)$ \\
Platelet count $<100 \times 10^{9} / \mathrm{L}, n(\%)$ & $4(3.8)$ & $4(3.8)$ \\
Intolerance, $n(\%)$ & $17(16.0)$ & $17(16.0)$ \\
Leg ulcer, $n(\%)$ & $11(10.4)$ & $11(10.4)$ \\
Fever, $n(\%)$ & $3(2.8)$ & $3(2.8)$ \\
Mucocutaneous manifestations, $n(\%)$ & $3(2.8)$ & $3(2.8)$ \\
\hline
\end{tabular}

$H U$ hydroxyurea

*Data are median (range) 
least 3 months. Therefore, no patient fulfilled criterion one to three of the ELNo (Table 1). Five patients (4.7\%) had occurrence of cytopenia at the lowest dose of HU to induce response. Anemia (hemoglobin $<10.0 \mathrm{~g} / \mathrm{dL}$ ) and thrombocytopenia (platelet count $\left.<100 \times 10^{9}\right)$ occurred in one $(0.9 \%)$ and four patients (3.8\%), respectively. No neutropenia (neutrophil count $<1.0 \times 10^{9}$ ) was recorded.

Seventeen patients $(16.0 \%)$ were intolerant to HU. Leg ulcers appeared in 11 patients $(10.4 \%)$. Three patients (2.8\%) had drug-induced fever. In three patients $(2.8 \%)$, HU was discontinued because of mucositis.

\section{Modified ELN criteria (ELNm)}

Resistance occurred in 25 patients $(23.6 \%)$ when applying the ELNm. Eighteen patients (16.6\%) required of phlebotomy to control hematocrit $<45 \%$. One patient $(0.9 \%)$ had leukocytosis $>10.0 \times 10^{9} / \mathrm{L}$. One patient $(0.9 \%)$ had thrombocytosis $>400 \times 10^{9} /$ L. No patient had palpable splenomegaly. Five patients $(4.7 \%)$ developed cytopenia at the lowest dose of HU to induce response. Anemia $(\mathrm{Hb}<10.0 \mathrm{~g} / \mathrm{dL})$ and thrombocytopenia (platelet count $<100 \times 10^{9}$ ) occurred in one $(0.9 \%)$ and four patients $(3.8 \%)$, respectively. No neutropenia (neutrophil count $<1.0 \times 10^{9}$ ) was recorded.

\section{Discussion}

In this study, we analyzed resistance/intolerance to HU in 106 patients with PV treated at the University Hospitals of Leuven between 1990 and 2016. Both the original ELN criteria and the modified ELN criteria as used in the RESPONSE trials [24, 25], were applied.

HU resistance/intolerance, as defined by the ELNo, has been analyzed in two previous studies in patients included in the Spanish Registry. One study included $261 \mathrm{PV}$ patients and recorded resistance in $11.5 \%$ and intolerance in $12.6 \%$ of patients [20]. A more recent study included $890 \mathrm{PV}$ patients and showed a resistance and intolerance rate of $5.7 \%$ and $10.7 \%$ respectively [21]. In these studies, the prognostic significance of HU resistance, defined by the ELNo, was shown. When applying the ELNo to our PV database, $4.7 \%$ of patients were resistant and $16.0 \%$ of patients were intolerant to $\mathrm{HU}$, like the data of the Spanish Registry.

Because of its prognostic significance, it is important to identify PV patients with HU resistance as defined by the ELNo. This subgroup of patients' needs second-line therapy to achieve effective disease control. However, at our center, no patient received a minimum dose of $2 \mathrm{~g}$ of $\mathrm{HU}$ a day. As such, only patients with cytopenia at the lowest dose of HU to achieve partial or complete hematological response (criterion 4, Table 1) were resistant to HU, following the ELNo. This high dose of HU ( $2 \mathrm{~g}$ or more a day) does not seem to be a common practice, as the median daily dose of $\mathrm{HU}$ in patients included in the Spanish Registry was 1000 mg (range 250 2500). The lowest possible dose is prescribed to minimize the risk of adverse effects [13, 22]. A possible explanation for not prescribing $2 \mathrm{~g} \mathrm{HU}$ or more daily, is the pragmatic combined approach of low-dose HU together with sporadic intermittent phlebotomies to achieve adequate hematocrit control in some PV patients. This means that intermittent phlebotomies are accepted and tolerated by the patient, rather than further increasing the dose of $\mathrm{HU}$ when the need of phlebotomies appears. Keeping the low-dose HU keeps the phlebotomyfrequency low.

As such, the modified ELN criteria seem to be more appropriate for daily clinical practice. When applying the ELNm, resistance and intolerance occurred in 23.6 and $16.0 \%$ of patients, respectively. Not surprisingly, the HU intolerance rate is equal between ELNo and ELNm and the HU resistance rate is much higher in ELNm compared to ELNo. However, the prognostic significance of $\mathrm{HU}$ resistance is only proven when using the ELNo and still needs to be confirmed when using the ELNm. Due to relatively small number of patients in this study and the short median time of follow-up for, no conclusions can be made regarding the prognostic value of the ELNm.

Intolerance to $\mathrm{HU}$ does not have any prognostic significance; however, it is clinically relevant. HU needs to be discontinued in this subgroup of patients who experience unacceptable side effects due to therapy with HU. These patients are also eligible for second line therapy. Both ELNo and ELNm do not include worsening of PV-related symptoms such as constitutional symptoms and pruritus. However, patients with PV have an impaired quality of life due to a significant symptom burden. When HU has little effect in controlling these symptoms [22, 24, 25], this also is an indication for second-line therapy to reduce the potentially severe symptom burden of PV.

Before the advent of the JAK1/JAK2 inhibitor ruxolitinib, PV patients with HU resistance and intolerance had few therapeutic alternatives. Interferon is recommended as first- or second-line therapy in PV [14]; however, it is not licensed for treatment of PV in many European countries [15, 27].

Ruxolitinib has been evaluated in the RESPONSE and RESPONSE-2 trial [24, 25], comparing ruxolitinib versus the best available therapy in HU-resistant or HU-intolerant PV patients. As inclusion criteria, the ELNm criteria were used. This modification allowed to include more patients in the clinical trials and extend the clinical indication of ruxolitinib. Although it must be noted that the prognostic significance of $\mathrm{HU}$ resistance has only been proven using the ELNo.HU resistance and intolerance is defined here by the ELNm. Ruxolitinib was superior to standard therapy in achieving hematocrit control and in reduction of symptom burden [24, 25, 28]. In the 80week follow-up study of the RESPONSE trial, patients treated with ruxolitinib had a lower thrombo-embolic event rate per 
100 patient years (1.8 in the ruxolitinib group versus 8.2 in the best available therapy group) [29]. This suggests all patients with HU resistance/intolerance defined by the ELNm may benefit from therapy with ruxolitinib.

In conclusion, detection of $\mathrm{HU}$ resistance in PV patients is important because of its prognostic significance (proven when using the ELNo) and because of recent availability of more second line treatment options. In our hands, incidence of HU resistance in PV patients is $23.6 \%$ when applying the ELNm. This rate is only $4.7 \%$ with the ELNo. In our practice, no PV patient received "at least 2 -g HU daily for 3 months." As such, the ELNm seem better adapted for daily clinical use. However, the prognostic value of $\mathrm{HU}$ resistance in PV, when defined by the ELNm, still needs to be confirmed.

Authorship contributions All authors declare that they have participated in writing the paper and have seen and approved the final version of the paper.

\section{Compliance with ethical standards}

Conflict of interest Thomas Demuynck, Gregor Verhoef, Michel Delforge, and Peter Vandenberghe have no conflict of interest to declare. Timothy Devos did participate in an advisory board for Novartis and Gilead.

\section{References}

1. Vannucchi AM (2010) Insights into the pathogenesis and management of thrombosis in polycythemia vera and essential thrombocythemia. Intern Emerg Med 5(3):177-184

2. Arber DA, Orazi A, Hasserjian R, Thiele J, Borowitz MJ, Le Beau MM et al (2016) The 2016 revision to the World Health Organization classification of myeloid neoplasms and acute leukemia. Blood 127(20):2391-2405

3. Moulard O, Mehta J, Fryzek J, Olivares R, Igbal U, Mesa R (2014) Epidemiology of myelofibrosis, essential thrombocythemia, and polycythemia vera in the European Union. Eur J Haematol 92(4): 289-297

4. Tefferi A (2010) Novel mutations and their functional and clinical relevance in myeloproliferative neoplasms: JAK2, MPL, TET2, ASXL1, CBL, IDH and IKZF1. Leukemia 24(6):1128-1138

5. Tefferi A, Rumi E (2013) Finazzi Gea. Survival and prognosis among 1545 patients with contemporary polycythemia vera: an international study. Leukemia 27(9):1874-1881

6. Marchioli R, Finazzi G, Landolfi R, Kutti J, Gisslinger H, Patrono C, Marilus R, Villegas A, Tognoni G, Barbui T (2005) Vascular and neoplastic risk in a large cohort of patients with polycythemia vera. J Clin Oncol 23(10):2224-2232

7. Cerquozzi S, Tefferi A (2015) Blast transformation and fibrotic progression in polycythemia vera and essential thrombocythemia: a literature review of incidence and risk factors. Blood Cancer J 5:e366

8. Geyer H, Scherber R, Kosiorek H, Dueck AC, Kiladjian JJ, Xiao Z, Slot S, Zweegman S, Sackmann F, Fuentes AK, HernándezMaraver D, Döhner K, Harrison CN, Radia D, Muxi P, Besses C, Cervantes F, Johansson PL, Andreasson B, Rambaldi A, Barbui T, Bonatz K, Reiter A, Boyer F, Etienne G, Ianotto JC, Ranta D, Roy
L, Cahn JY, Maldonado N, Barosi G, Ferrari ML, Gale RP, Birgegard G, Xu Z, Zhang Y, Sun X, Xu J, Zhang P, te Boekhorst PA, Commandeur S, Schouten H, Pahl HL, Griesshammer M, Stegelmann F, Lehmann T, Senyak Z, Vannucchi AM, Passamonti F, Samuelsson J, Mesa RA (2016) Symptomatic profiles of patients with polycythemia Vera: implications of inadequately controlled disease. J Clin Oncol 34(2):151-159

9. Anderson LA, James G, Duncombe AS, Mesa R, Scherber R, Dueck AC, de Vocht F, Clarke M, McMullin MF (2015) Myeloproliferative neoplasm patient symptom burden and quality of life: evidence of significant impairment compared to controls. Am J Hematol 90(10):864-870

10. Mesa R, Miller CB, Thyne M, Mangan J, Goldberger S, Fazal S, Ma X, Wilson W, Paranagama DC, Dubinski DG, Boyle J, Mascarenhas JO (2016) Myeloproliferative neoplasms (MPNs) have a significant impact on patients' overall health and productivity: the MPN landmark survey. BMC Cancer 16:167

11. Marchioli R, Finazzi G, Specchia G, Cacciola R, Cavazzina R, Cilloni D, de Stefano V, Elli E, Iurlo A, Latagliata R, Lunghi F, Lunghi M, Marfisi RM, Musto P, Masciulli A, Musolino C, Cascavilla N, Quarta G, Randi ML, Rapezzi D, Ruggeri M, Rumi E, Scortechini AR, Santini S, Scarano M, Siragusa S, Spadea A, Tieghi A, Angelucci E, Visani G, Vannucchi AM, Barbui T, CYTOPV Collaborative Group (2013) Cardiovascular events and intensity of treatment in polycythemia vera. N Engl J Med 368(1):22-33

12. Rumi E, Cazzola M (2017) Diagnosis, risk stratification, and response evaluation in classical myeloproliferative neoplasms. Blood 129(6):680-692

13. McMullin MF, Wilkins BS, Harrison CN (2016) Management of polycythaemia vera: a critical review of current data. Br J Haematol 172(3):337-349

14. Barbui T, Tefferi A, Vannucchi AM, Passamonti F, Silver RT, Hoffman R, Verstovsek S, Mesa R, Kiladjian JJ, Hehlmann R, Reiter A, Cervantes F, Harrison C, Mc Mullin MF, Hasselbalch HC, Koschmieder S, Marchetti M, Bacigalupo A, Finazzi G, Kroeger N, Griesshammer M, Birgegard G, Barosi G (2018) Philadelphia chromosome-negative classical myeloproliferative neoplasms: revised management recommendations from European LeukemiaNet. Leukemia 32(5):1057-1069

15. Griesshammer M, Gisslinger H, Mesa R (2015) Current and future treatment options for polycythemia vera. Ann Hematol 94(6):901-910

16. Reiter A, Harrison C (2016) How we identify and manage patients with inadequately controlled polycythemia Vera. Curr Hematol Malig Rep 11(5):356-367

17. Kiladjian JJ, Chevret S, Dosquet C, Chomienne C, Rain JD (2011) Treatment of polycythemia vera with hydroxyurea and pipobroman: final results of a randomized trial initiated in 1980. J Clin Oncol 29(29):3907-3913

18. Finazzi G, Caruso V, Marchioli R, Capnist G, Chisesi T, Finelli C, Gugliotta L, Landolfi R, Kutti J, Gisslinger H, Marilus R, Patrono C, Pogliani EM, Randi ML, Villegas A, Tognoni G, Barbui T, ECLAP Investigators (2005) Acute leukemia in polycythemia vera: an analysis of 1638 patients enrolled in a prospective observational study. Blood 105(7):2664-2670

19. Antonioli E, Guglielmelli P, Pieri L, Finazzi M, Rumi E, Martinelli V, Vianelli N, Luigia Randi M, Bertozzi I, de Stefano V, Za T, Rossi E, Ruggeri M, Elli E, Cacciola R, Cacciola E, Pogliani E, Rodeghiero F, Baccarani M, Passamonti F, Finazzi G, Rambaldi A, Bosi A, Cazzola M, Barbui T, Vannucchi AM, On behalf of the AGIMM Investigators (2012) Hydroxyurea-related toxicity in 3,411 patients with Ph'-negative MPN. Am J Hematol 87(5):552-554

20. Alvarez-Larran A, Pereira A, Cervantes F, Arellano-Rodrigo E, Hernandez-Boluda JC, Ferrer-Marin F, Angona A, Gomez M, Muina B, Guillen H, Teruel A, Bellosillo B, Burgaleta C, Vicente $\mathrm{V}$, Besses C (2012) Assessment and prognostic value of the 
European LeukemiaNet criteria for clinicohematologic response, resistance, and intolerance to hydroxyurea in polycythemia vera. Blood 119(6):1363-1369

21. Alvarez-Larran A, Kerguelen A, Hernandez-Boluda JC, Perez-Encinas M, Ferrer-Marin F, Barez A et al (2016) Frequency and prognostic value of resistance/intolerance to hydroxycarbamide in 890 patients with polycythaemia vera. Br J Haematol 172(5):786-793

22. Parasuraman S, DiBonaventura M, Reith K, Naim A, Concialdi K, Sarlis NJ (2015) Patterns of hydroxyurea use and clinical outcomes among patients with polycythemia vera in real-world clinical practice: a chart review. Exp Hematol Oncol 5:3

23. Barosi G, Birgegard G, Finazzi G, Griesshammer M, Harrison C, Hasselbalch $\mathrm{H}$ et al (2010) A unified definition of clinical resistance and intolerance to hydroxycarbamide in polycythaemia vera and primary myelofibrosis: results of a European LeukemiaNet (ELN) consensus process. Br J Haematol 148:961-963

24. Vannucchi AM, Kiladjian JJ, Griesshammer M, Masszi T, Durrant S, Passamonti F, Harrison CN, Pane F, Zachee P, Mesa R, He S, Jones MM, Garrett W, Li J, Pirron U, Habr D, Verstovsek S (2015) Ruxolitinib versus standard therapy for the treatment of polycythemia vera. N Engl J Med 372(5):426-435

25. Passamonti F, Griesshammer M, Palandri F, Egyed M, Benevolo G, Devos T, Callum J, Vannucchi AM, Sivgin S, Bensasson C, Khan M, Mounedji N, Saydam G (2017) Ruxolitinib for the treatment of inadequately controlled polycythaemia vera without splenomegaly (RESPONSE-2): a randomised, open-label, phase $3 b$ study. Lancet Oncol 18(1):88-99
26. Vannucchi AM, Kiladjian JJ, Griesshammer M, Masszi T, Durrant S, Passamonti F et al (2015) Ruxolitinib versus Standard Therapy for the Treatment of Polycythemia Vera. https://doi.org/10.1056/ NEJMoa1409002

27. Silver RT (2006) Long-term effects of the treatment of polycythemia vera with recombinant interferon-alpha. Cancer 107(3):451-458

28. Mesa R, Verstovsek S, Kiladjian JJ, Griesshammer M, Masszi T, Durrant S, Passamonti F, Harrison CN, Pane F, Zachee P, Zhen H, Jones MM, Parasuraman S, Li J, Côté I, Habr D, Vannucchi AM (2016) Changes in quality of life and disease-related symptoms in patients with polycythemia vera receiving ruxolitinib or standard therapy. Eur J Haematol 97(2):192-200

29. Verstovsek S, Vannucchi AM, Griesshammer M, Masszi T, Durrant S, Passamonti F, Harrison CN, Pane F, Zachee P, Kirito K, Besses C, Hino M, Moiraghi B, Miller CB, Cazzola M, Rosti V, Blau I, Mesa R, Jones MM, Zhen H, Li J, Francillard N, Habr D, Kiladjian JJ (2016) Ruxolitinib versus best available therapy in patients with polycythemia vera: 80 -week follow-up from the RESPONSE trial. Haematologica 101(7):821-829

Publisher's note Springer Nature remains neutral with regard to jurisdictional claims in published maps and institutional affiliations. 